\title{
The grammar of proposals for joint activities
}

\author{
Sandra A. Thompson, Barbara A. Fox, and \\ Chase Wesley Raymond ${ }^{2}$ \\ ${ }^{1}$ UC Santa Barbara $\left.\right|^{2}$ University of Colorado, Boulder
}

The action of proposing has been studied from various perspectives in research on talk-in-interaction, both in mundane as well as in institutional talk. Aiming to exemplify Interactional Linguistics as a drawing together of insights from Linguistics and Conversation Analysis, we explore the grammar of proposals and the stances displayed by participants in making proposals in the context of joint activities, where a future or hypothetical activity is being put forth as something the speaker and recipient(s) might do together. Close examination of interactions among American Englishspeaking adults reveals four recurrent grammatical formats for issuing proposals: Let's, Why don't we, Modal Declaratives, and Modal Interrogatives. We argue that these four formats for doing proposing within a joint activity are used in socially distinct environments, contributing to a growing understanding of the fit between entrenched linguistic patterns and the social work they have evolved to do.

Keywords: proposal, joint activities, (grammatical) format, let's, grammar, deontic strength

\section{Introduction}

Michael Tomasello has written compellingly about what makes us uniquely human. Tomasello argues that, compared to other species, not only are humans "especially social", they are also "especially cooperative" (2014:87). For those of us committed to uncovering the nuts and bolts of human social interaction, a key question is how such cooperation with others manifests itself and is accomplished in the immediacy of quotidian conduct. In this paper, we explore this question through examination of the ways that participants make proposals to coordinate joint activities - that is, activities that participants will do together. 
Proposal-making can take many different grammatical and embodied forms, especially as one takes a cross-linguistic and cross-cultural perspective; our primary interest here is in analyzing the social-interactional factors that motivate selection from among these options in real-time interaction.

Proposals have attracted the attention of scholars studying a range of interactional phenomena. Stevanovic (2012) focuses on proposals in joint decisionmaking; in this and subsequent research on decision-making, a primary consideration is the negotiation between the proposer and the recipient(s) as to rights and obligations for arriving at decisions made jointly. Zinken and Ogiermann (2011) study family interactions in Polish and examine how grammar is used to design proposals and directives that do not specify who is to carry them out. Robinson and Kevoe-Feldman (2016) analyze the distinctions between proposing arrangement details and soliciting a proposal for arrangements, focusing on the accountability of such courses of action. In the realm of children's interaction, Goodwin (1990:109-113) and Stivers and Sidnell (2016) study how children at play formulate proposals for what they will jointly do next, while Asmuß and Oshima (2012) and Stevanovic (2013) consider proposals in meetings in Danish and Finnish respectively. How proposals are responded to is a key consideration in this body of work (see especially Asmuß \& Oshima 2012; Barnes 2007; Houtkoop 1987; Lindström 2017; Stevanovic 2013; Stevanovic \& Peräkylä 2012; Stevanovic et al. 2020), and responses to proposing actions also figure in the argument we develop here.

Couper-Kuhlen (2014) posits distinctions among four actions involved in getting others to do something, these distinctions being based on who is to benefit. Proposals, she argues, can be distinguished from similar types of actions - specifically suggestions, requests, and offers - in that they are used when the activity is framed as benefitting both speaker and hearer, and this characterization fits our collection as well (see also Clayman \& Heritage 2014).

In this inaugural issue of Interactional Linguistics, we focus on a specifically grammatical way to zero in on the work that participants are doing when they issue a proposal. Our concern here is proposals for how to manage the organization of joint activities - that is, turns in which an activity is being put forth as something speaker and recipient(s) might do together. ${ }^{1}$ The argument we present here will be less oriented to distinguishing 'proposals' from other social actions involved with securing others' cooperation, and also less focused on the unfolding of joint decision-making sequences. Our interest, instead, is in the social-interactional motivations for the choice of grammatical formats for

1. Proposals have thus sometimes been seen as a type of "recruitment" (Floyd et al. 2020; Kendrick \& Drew 2016). 
proposal-making. We will be investigating how adults speaking American English make proposals for joint activities in everyday interactions - in other words, the role that proposal formulations play as joint activities are "talked into being" (Heritage 1984b: 290). We then use these observations regarding the routine environments of occurrence of different formats to offer a theoretical contribution to the study of grammar as a participant's resource in interaction.

The present study thus builds on previous work examining the relation between grammatical form and other recruitment-related actions. Researchers have drawn on such interactional features as contingency and entitlement (Curl 2006; Curl \& Drew 2008; Fox \& Heinemann 2016), expectation of being complied with (Raymond et al. forthcoming), recipient's current activity trajectory (Zinken \& Deppermann 2017), and deontic stance (Couper-Kuhlen \& Thompson forthcoming) to account for variation in grammatical format choice in request, offer, and advice-giving sequences. In alignment with what Raymond et al. (2021) have found in the case of offers, our study of proposals focuses on the estimation of proposers as to the likelihood of their proposal being embraced.

\section{Establishing a collection of joint-activity proposals}

In this section, we describe our collection-building process (see Clift \& Raymond 2018), which we will use to motivate exploration of the particular formats we target in this study.

In building our collection, we considered moments in an interaction where a proposal for a joint activity occurs - that is, turns in which an activity is put forth as something speaker and recipient(s) might do together. We first collected each of these from a large corpus of video-recorded interactions and audio-recorded phone calls. These data include our own data files, 'classic' CA corpora, ${ }^{2}$ and a new set of video recordings of people engaged in joint manual activities such as cooking, baking, and painting a table (noted with 'JA' in the relevant extracts). This latter set of recordings was made by the participants themselves, with their own cameras, and were transcribed by us. These data sources yielded a rich collection of over 200 proposals.

As we began to examine the grammar of these turns, we first noted variation in the person(s) grammatically built as the doer(s) of the proposed activity. For the purposes of the present study we focus on first-person plural forms, which

2. For more information on and discussion of these corpora, see Hoey and Raymond (forthcoming). 
build the jointness of the proposed activity into the grammar of the proposal (e.g., let's cut these out vs. I'll walk down there and meet you.).

Four recurrently used first-person plural formats emerged from our analysis of the data. These formats are:

- Let's

- Why don't we (WDW)

- Modal Declaratives

- Modal Interrogatives

as exemplified in (1)-(4) below:

(1) let's put the fur on the wall

(2) well why don't we talk about it later then

(3) maybe we can get together for dinner

(4) should we make a salad too at the same time?

In (2)-(4), the first-person plural pronoun we is used, while in let's in (1), there is a contracted first-person plural us. Importantly, given our specific interest in joint activities, we did not include all instances of these grammatical formats with a first-person plural pronoun; for example, it is well-known that we/us is sometimes used in cases where the action will not actually be carried out by 'us' together - as in the 'nurses' we', the 'royal we', and so on (see Du Bois 2012, Section 4). Similarly excluded were first-person plural utterances which in their local context acted as directives to the recipient and did not name joint activities. We did not include formulaic let's expressions (e.g., let's face it; let's see) on the grounds that, rather than serving as vehicles for joint activities, fixed expressions such as these have more 'emancipated' uses. ${ }^{3}$ It was not criterial that these formats be responded to in a specific way, though often a recipient response will be part of our analysis.

These four grammatical formats, exemplified in (1)-(4), differ in their composition. We can describe these differences in terms of Bybee's (2010) characterization of 'constructions' as ranging from the most lexically specific to the most schematic. Of the four English proposal formats, the first two, Let's and Why don't we (WDW), are the most lexically specific, although our Modal Interrogative category is also highly restricted lexically, showing only should we. The category of Modal Declaratives, in contrast, shows a slightly greater set of modal verbs but is

3. In our data, let's see is never issued as a proposal for speaker and recipient to look at something together, for example. For self-authorizing lemme (= let me), see Hoey (2020). On formulaicity and 'emancipation', see Haiman (1998). 
still highly restricted, the verbs should, could, and can making up more than $90 \%$ of our Modal Declarative cases. ${ }^{4}$

These formats also differ in their distribution across our collection, Modal Declaratives are by far the most frequent, and the Modal Interrogative and WDW formats are relatively quite rare, as can be seen in Table 1 .

Table 1. Frequency of each format in our collection

\begin{tabular}{lr}
\hline Modal Declaratives & 86 \\
Let's & 56 \\
WDW & 11 \\
Modal Interrogatives & 9 \\
Total & $\mathbf{1 6 2}$ \\
\hline
\end{tabular}

Close examination of the four grammatical formats just described reveals that joint-activity proposals are particularly fitted to the environments in which they are produced. We will show that participants orient to these formats in terms of their relative strength along a cline, indexing what they take to be the recipient's disposition toward accepting the proposal. That is, we claim that speakers choose among the grammatical formats examined here according to how strongly the recipient has shown themselves to be disposed toward accepting the proposal. Specifically, Let's proposals are used in the context of the strongest displays of a disposition toward acceptance, and Modal Interrogatives are used in the context of the weakest such displays, with WDW proposals and Modal Declaratives falling in between, as schematized in (5),

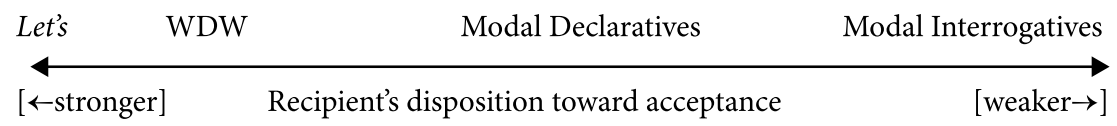

In what follows, we present evidence to support this relative positioning of our four target grammatical formats along this cline (Section 3), after which we will discuss in greater detail the fittedness of these particular formats to contexts in which they are produced (Section 4). Section 5 offers some of the theoretical implications of our findings.

4. Other fixed expressions for making proposals that we authors agree that we've heard are what if we..., I-say we/what-do-you-say we..., but we found no such cases in our data. 


\section{The grammar of proposals for joint activities}

In this section, we describe and illustrate the primary interactional environments in which we find each of our four formats as they are used in joint-activity proposals. A more detailed comparison of the formats vis-à-vis one another will be offered in Section 4.

\subsection{Let's}

In our data, speakers regularly use Let's in contexts where going forward with the specific joint activity they propose is guaranteed, or at least very likely. Evidence for this claim is found primarily in the talk and embodied conduct of the participants prior to the Let's turn. As we will demonstrate, in these cases, recipients have already shown themselves to be very strongly disposed toward proceding, not just with any activity, but with the particular joint activity that their interlocutor formulates with Let's. We argue that the Let's format therefore displays a stance that recipient compliance is strongly expected or assumed, and thus that the joint activity formulated in the proposal is highly likely to come to fruition.

Consider Extract (6). Here, housemates Jennifer, Bonnie, and Teresa are sitting at a table having lunch. After a short lapse, Jennifer launches a new sequence in line 1 with what should we do today.

(6) [Housemates_35_24:30]

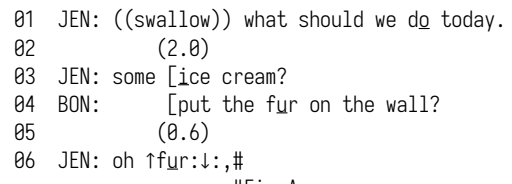

\#Fig A

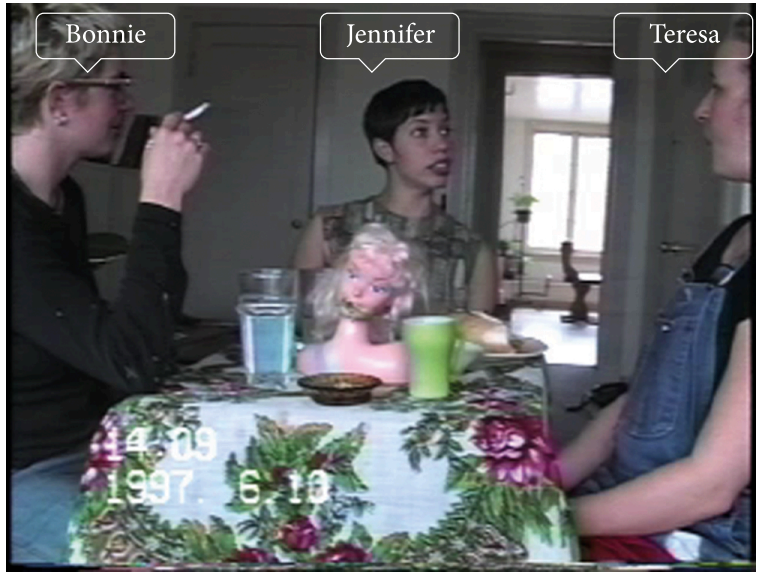

Fig A 


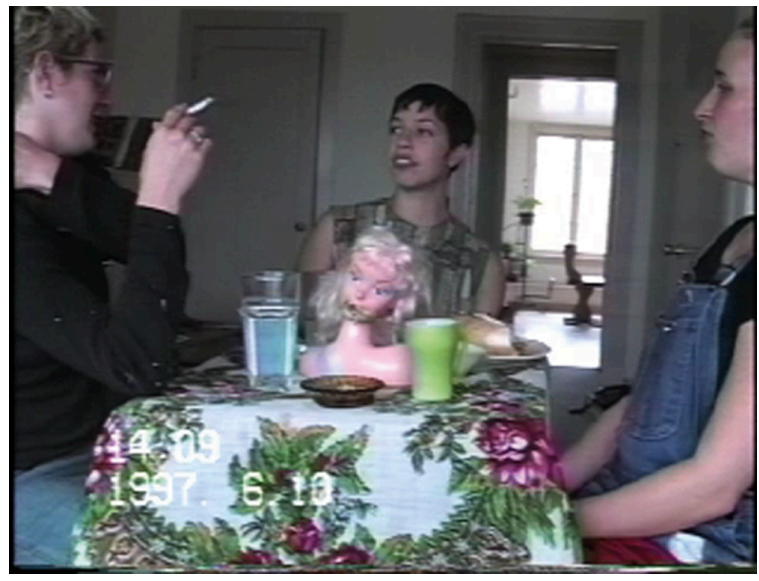

Fig B

11 TER: Well I put that

12 TER: Did you check out the epoxy this morning? [24:40]

As neither of Jennifer's recipients self-selects to respond to her proposal solicitation at line 1, what should we do today, a 2-second silence emerges, after which Jennifer herself produces a candidate activity with some ice cream? (line 3 ). It is not clear whether she has in mind to eat or make ice cream, but in overlap with Jennifer's candidate activity, Bonnie responds to Jennifer's question in line 1 by suggesting that they put the fur on the wall? (line 4), produced with 'try-marked' intonation that offers it as a candidate joint activity (Sacks \& Schegloff 1979). Jennifer's $o h$-prefaced (Heritage 1984a) repeat of the noun from the prior turn - oh $\uparrow$ fur: $\downarrow$ :., (line 6) - orients to this proposal as having reminded her of an earlierdiscussed joint activity, namely the applying of fur fabric to some of the walls in the apartment that the three share; during line 6 Jennifer turns to face Teresa (Figure A).

Teresa aligns with the 'fur' proposal (line 8), and immediately after that Jennifer returns her gaze to Bonnie (Figure B) and ratifies Bonnie's proposal with ${ }^{\circ}$.pt=(l)et's put the fur on the wall ${ }^{\circ}$, (line 10). As it was Bonnie who originally offered this joint-activity idea, and Teresa has already shown herself to be on board with it, it is altogether unlikely that Jennifer's ${ }^{\circ} p t=(l) e t^{\prime}$ s put the fur on the wall- ${ }^{\circ}$, will be met with any resistance from Bonnie. We argue that the Let's format that Jennifer uses to issue her proposal both reflects and indexes a stance that Bonnie and Teresa are highly likely to agree to the 'putting the fur on the wall' joint activity. 
In the following case, a Let's-formatted proposal occurs not in responsive position, but following a pre-sequence that has received a go-ahead response (Schegloff 2007; Thompson, Fox \& Couper-Kuhlen 2015). Here five friends are beginning to paint a complex design on a table for graduation, and they've just started this recording at line 1 . There is a first Let's proposal from Eva - let's ( ) prioritize size (0.4) rather than (sides). (lines 2 and 6 ) - but as we do not have access to what happened before this turn, we can't analyze that particular proposal further, other than to say that the participants are in the midst of deciding how best to continue with the table-painting task. Our interest is in the new sequence that Ida launches in line 11 and directs specifically toward Leo, oh $>$ did you< bring scissors?.

(7) [JA-4_painttable_155259]
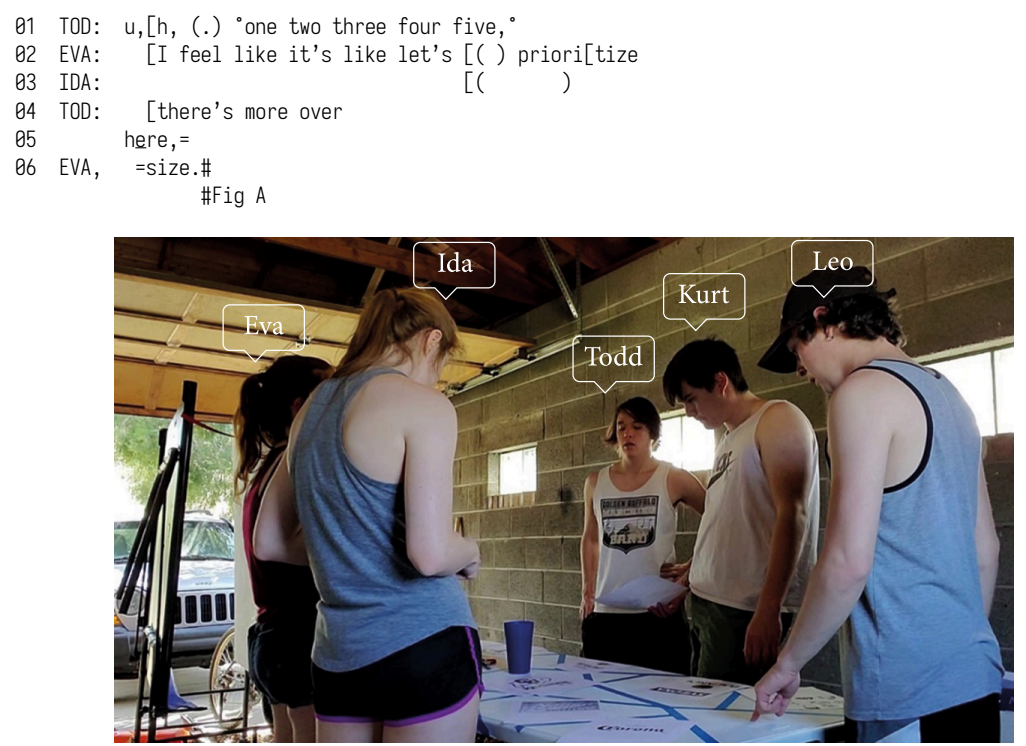

(0.4)

Fig A

EVA: rather than=

LEO: $=($ so, $)=$

EVA: $=($ sides $) .=$

KUR: $=(\quad[)$

IDA: [oh >did you< bring scissors?

(0.4)

LEO: yea:h.=

IDA: =let's [cut these out. let's start by >cutting them out<.=

LEO [they're\# right there. \#Fig B 


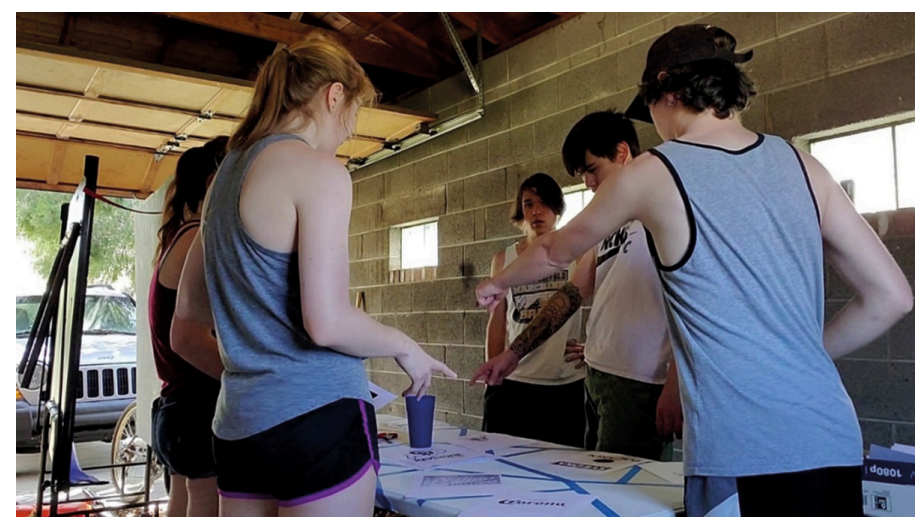

Fig B

16 LEO: =alright.

(0.3)

18 TOD: that'1l- that'll give us a little bit [better of a visual.

19 LEO:

20 IDA:

[ I can start

[and then I'll

Leo responds affirmatively to Ida's inquiry (line 14), and immediately begins orienting his body toward the scissors (which are on the other side of the table) by raising his left arm into a long point (Figure B) as he produces they're right there. (line 16). As Leo thus displays - both verbally, with the go-ahead yea:h, and corporeally, with his orientation toward the scissors - that he is on board with doing a scissors-related activity, Ida, in overlap, produces let's cut these out, (line 15). Since her primary recipient has now just indicated that he remembered to bring scissors to the activity, and is presently making moves toward using those scissors, Ida's proposal is produced in a context where success of the proposed joint activity is extremely likely; indeed, it is arguably already in progress. With the Let's format, Ida adopts this very stance, indexing assumed compliance on the part of her recipient (who does indeed comply; lines 16/19 and beyond the transcript reproduced here).

It is noteworthy that Ida immediately issues a second Let's proposal here that is slightly modified vis-à-vis the first: let's cut from the first becomes let's start by cutting in the second. For this second Let's proposal, Ida's intended recipients have changed: The conversation between the other three has stopped, and one (Todd) has even broken away entirely from their trio to orient to Ida's and Leo's search for the scissors. Ida's second version of the proposal is still Let's-framed, but the 'scope' of the proposed joint activity is smaller (start by cutting vs. cut) and is thus arguably easier to agree with for recipients who have not been directly involved in the path-clearing pre-sequence. In addition, in an activity where the shared objective is to trace images onto the table and then paint them, preparing the images for tracing (i.e., cutting them out; line 14) seems a logical - and possibly obligatory - 
first step. This may additionally contribute to the stance Ida takes in issuing her proposals.

Additional evidence for our claim that the Let's format is used to formulate proposals in environments where recipient compliance is essentially assumed can be found in contexts of direct reported speech (Holt 1996). In Extract (8), taken from a phone call, B launches a complaint about how her partner and his family always propose playing a card game called 'Asshole' when they go to visit.

(8) [CallHome_eng_5373_24:15]

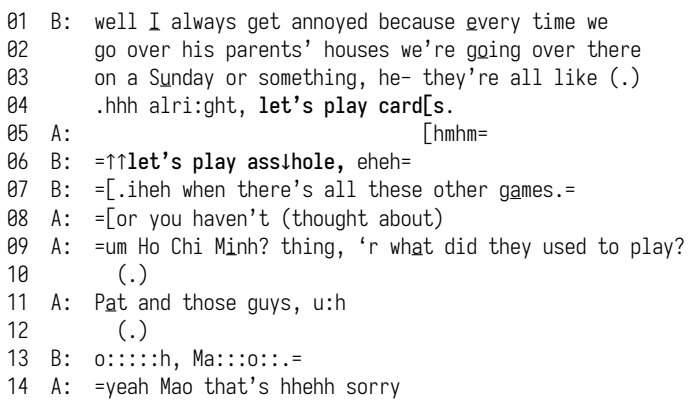

The point of the direct reported speech in this complaint is precisely to convey that B's partner and family assume a common interest in, and disposition toward, playing 'Asshole' (note also the self-repair from singular he- to the collective they're all; line 3), when in reality, from B's perspective, there's all these other games. (line 7) that they could play instead. That B formulates these reported speech events on behalf of her partner and his family with Let's adds further evidence for our claim by illustrating the routinization of this format to take a stance that recipient compliance is assumed - which is, after all, the reason B always get [s] annoyed (line 1), and is thus the core of her complaint. Our analysis thus both extends to, and is supported by, instances of reported speech, which were not infrequent in our collection. Moreover, this instance illustrates that while recipient disposition is indeed publicly displayed in the majority of the cases in our collection, it need not be. Proposers of joint activities may also use grammar in the service of presuming or attributing some stance to the recipient as regards the likelihood of their acceptance of the proposal - attributions which, as we see in this case, recipients may very well resist.

\subsection{Why don't we (WDW)}

Similar to Let's, the Why don't we (WDW) format is likewise produced in our data in contexts where prior talk and/or embodied conduct suggests that the jointactivity proposal will likely be successful. In the case of WDW, though, the pro- 
posal issues a compromise to a prior proposal, offer, or suggestion made earlier in the talk, either by the same speaker or by another, when that prior action has been met with some difficulty. In this context, speakers produce a WDW format to issue a proposal that is demonstrably geared toward salvaging some part of the problematized course of action while avoiding the oriented-to obstacle.

Consider Extract (9), in which a conflict has come up among the participants, and an open discussion about the conflict develops,

(9) Housemates

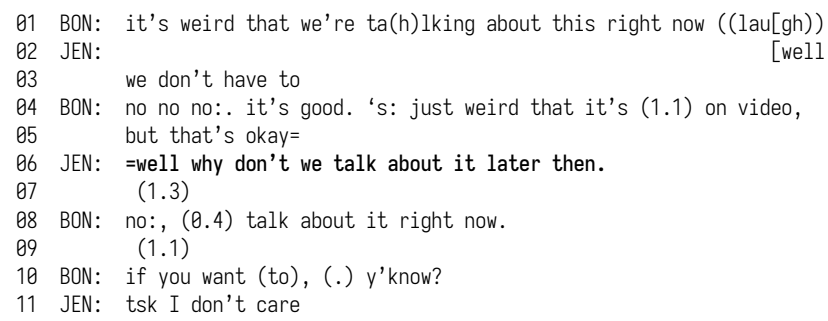

At line 1 Bonnie notes that it is weird to talk about the topic now - that is, while they're being recorded (lines 1 and 4). At line 2 Jennifer offers a suggestion - well we don't have to - which attends to Bonnie's concern and offers a different way forward. At line 4 Bonnie's no no no: dismisses Jennifer's suggestion (Stivers 2004), and suggests that it is okay to continue with the discussion, while also clarifying that it is specifically the fact that the interaction is being videotaped that is the problem. It is in this context that Jennifer produces well why don't we talk about it later then. (line 6) as a compromise proposal that will allow them to discuss what they both want to discuss, while avoiding the expressed problem of the videotaping. That this proposal is intended as a compromise in light of this obstacle is further reflected in the turn-final adverb then, which marks the turn as occasioned by the prior talk. In this case, Bonnie rejects the proposal, and the participants go on to continue their discussion of the conflict.

Extract (10) exhibits a similar pattern, a proposal being issued to address a difficulty that has arisen, a compromise being offered that will remove that difficulty from consideration. In this example, two friends are discussing preparations for a bridge party that will take place at a church and involve many tables of players. What is being discussed in this case is how best to organize the playing - e.g., with or without partners, how and when to change partners, etc. (The shaded area in lines 18 and 19 is Claire's hypothetical enactment of the bridge players trying to figure out where to go if they were to keep changing tables.) 
(10) [SBL_lo25-28]

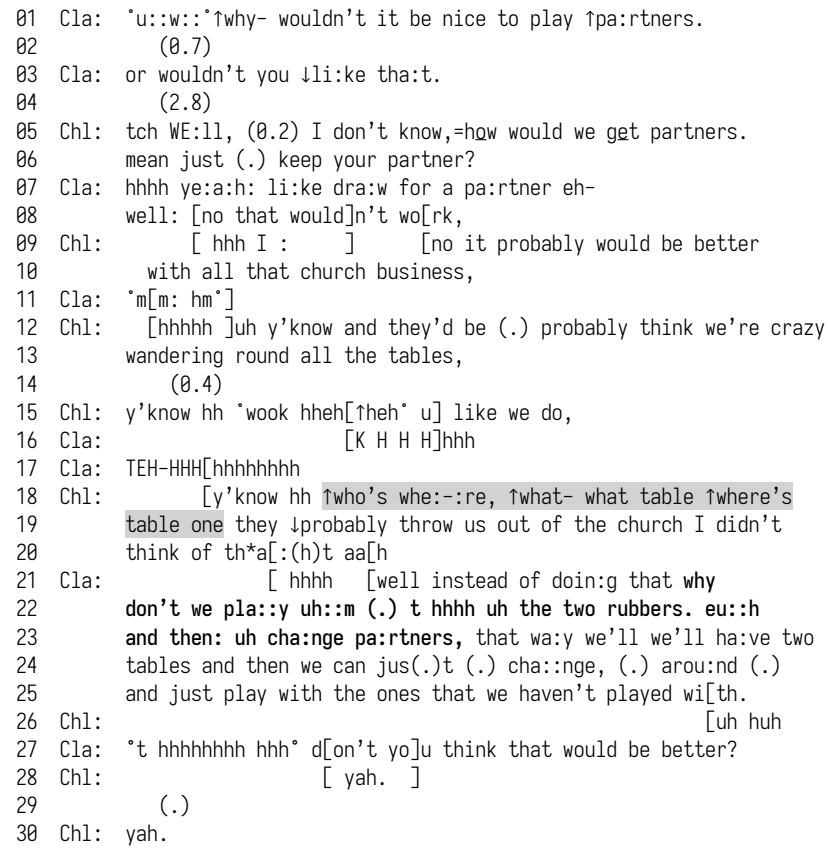

At line 1 Claire offers a proposal for something they might try for the upcoming party ( $\uparrow w h y$-wouldn't it be nice to play $\uparrow$ pa:rtners.); there is no uptake from Chloe at line 2, and at line 3 Claire backs down a bit with or wouldn't you $\downarrow$ li:ke tha:t. After a very long silence at line 4, Chloe provides a potential problem with Claire's proposal, and after Claire suggests a method for finding a partner, Chloe launches an extended account for why that wouldn't work in the setting of the church (lines 9-20). At line 21 Claire offers a compromise proposal, explicitly marked as such with instead of doin:g that, and then a WDW-formatted proposal: why don't we pla::y uh::m (.) thhhh uh the two rubbers. eu::h and then: uh cha:nge pa:rtners,. ${ }^{5}$ This proposal solves the problem raised by Chloe and still allows for a certain version of her original proposal to be realized - namely that they draw for partners (line 7). In this case, Claire even goes on to explicitly describe how this revised proposal takes into consideration the difficulties Chloe raised (lines 23-25), which Chloe acknowledges (lines 26, 28, 30).

Consider one further example of the WDW format in (11). Here, Julie and Amber are baking cookies together. Julie, at the counter, begins to mix the cookie

5. In "rubber bridge", a 'game' is won by the first team to score 100 or more points, and a 'rubber' is completed when one pair becomes the first to win two games. 
dough with her fork. At line 1, Amber takes a spoon from a drawer and offers it to Julie.

(11) [JA-10_cookies_13:10]

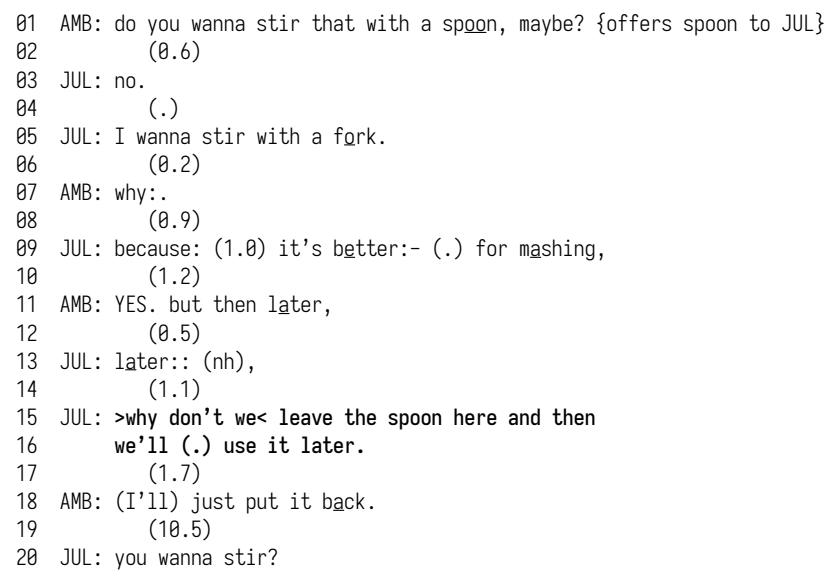

At line 3, Julie rejects the offer of the spoon, and provides a pro forma account at line 5 with I wanna stir with a fork. At line 7 Amber solicits a true account with why, (Bolden and Robinson 2011), which Julie ultimately provides (line 9). At line 11 Amber produces a designedly incomplete utterance (Koshik 2002) in which she hints that later a fork might be less appropriate - i.e., after the mashing is complete. At lines 15-16, Julie issues a compromise to the offer of a spoon, which is to not reject the spoon completely, but to not use it right now. At line 18 Amber rejects this compromise proposal and announces that she'll just put the spoon back in the drawer.

In each of the cases of WDW that we've examined here, an overt suggestion or proposal is made, and then there is resistance to it from the recipient(s) - i.e., some sort of problem with it is expressed or oriented to. The WDW-formatted proposal is then produced, offering a kind of 'bridging' proposal; in each case, the new proposal keeps something of the original proposal but modifies another facet of it. In other words, none of these compromise proposals completely rejects the suggestion that is under discussion; rather they offer a modification to it. In Extract (11), the proposal is modified to change partners only after 'two rubbers'; in Extract (12), the modification is to have the discussion, but later, without the video camera; and in Extract (13), the speaker proposes to use the spoon, but later. We argue that this format indexes a stance that compliance from the recipient is likely, as the proposal is offered in favor of a goal that the recipient already showed themselves to be on board with were it not for this difficulty - a difficulty that the WDW proposal aims specficially to address. 


\subsection{Modal Declaratives}

With the use of a Modal Declarative format, the speaker takes the stance that the recipient is more likely than not to endorse the proposed joint activity. As we have seen in the prior sections, in the context of a recipient who has already shown a disposition toward acceptance, we argue that proposers use a format that reflects this biased expectation toward acceptance. As we will see, though, in the case of Modal Declaratives, while recipients have shown themselves to be generally disposed to some future joint activity, they have not yet taken a stance toward the particular joint activity being proposed, as in the case of Let's or WDW. It is precisely in this context, which requires an additional inferential step on the part of the participants, that we find Modal Declarative proposals.

Proposal recipients can publicly display their disposition toward accepting a forthcoming action in a range of ways, and would-be proposers can be more or less active in soliciting such displays in advance of issuing their proposals. One practice through which would-be proposers can solicit recipient buy-in prior to issuing the proposal itself is to launch a pre-sequence, as we saw above in Extract (7). In the following Examples (12) and (13) the proposers first use general pre's (indicated with $->$ ) to check recipient availability. Recipients then produce a 'go-ahead' response $(=>)$. It is this context of a recipient having demonstrably shown themselves to be likely disposed toward accepting some future base action where we find proposers issuing Modal Declarative proposals $\left({ }^{*}>\right.$, bolded). In (12), Bob proposes maybe we can uh have a last minute poker ga:me or something. (lines 9-10).

(12) [Tomorrow_night_1_SF2_12:54]

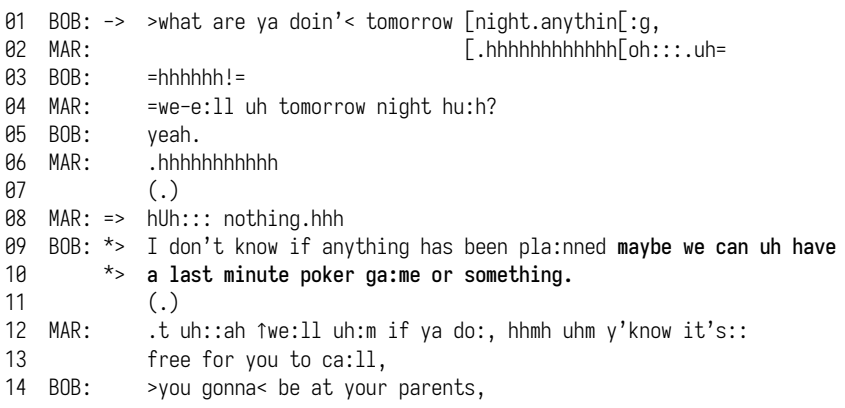

And in (13), following a discussion of Geri's inability to see someone recently, Shirley proposes that, when the individual in question is home for the Christmas holidays, perhaps they all $>$ can $<$ get together for dinner. (lines 10-11).

(13) [Geri \& Shirley]

$\begin{array}{ll}01 \text { Ger: } & \text { and it doesn't matter at this point I've waited this long } \\ 02 & \text { I [can (wait). }\end{array}$ 


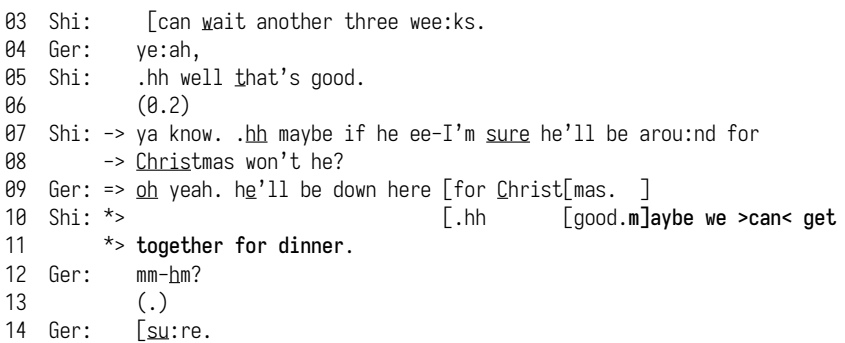

In this second case, note that Shirley even cuts off her nascent maybe if he eein line 7 in favor of the pre-sequence. Geri's confirmation, thereby issuing a goahead, provides the context for Shirley's Modal Declarative maybe we $>$ can $<$ get together for dinner. (lines 10-11).

Note that the pre-sequences we find in the Modal Declarative examples are far more 'generic' (see Schegloff 2007:48-53) than those we saw earlier in cases of Let's. In Extract (12), for example, the proposer has received a go-ahead response that indicates availability and thus a general disposition toward accepting some forthcoming base action; but an indication of availability does not show the recipient to be disposed toward accepting the particular joint activity being proposed i.e., a poker game. Indeed other, non-poker-related base actions might very well have occurred in this position. This contrasts with the more specific pre-sequence in (7) regarding the scissors, where asking if the recipient remembered to bring the scissors is produced and understood (by speaker and multiple recipients) as unambiguously preliminary to a more specific base action - namely one that will involve use of those scissors. We argue that speakers orient to this distinction in their particularized uses of Let's vs. Modal Declaratives.

Indeed, so normative is the [pre- $\rightarrow$ go-ahead $\rightarrow$ Modal Declarative] proposal sequence that we even find it in reported speech, as in (14), where Nancy is reporting a recent meeting with a potential romantic partner.

(14) [nbo10-9]

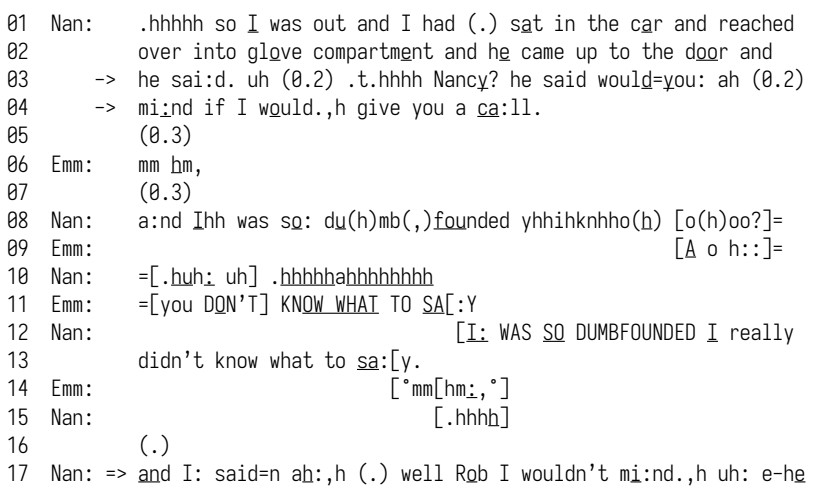




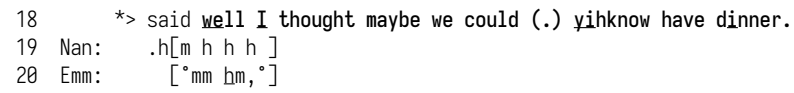

As part of Nancy's telling, she reports the pre-sequence launched by the gentleman in question (lines 3-4). After describing her 'dumbfoundedness' at hearing this (across lines 8-15), she then returns to the reported speech event in line 17. Here she reports both her own go-ahead - and I: said=n a $\underline{h}:: h$ (.) well Rob I wouldn't mi:nd., h (line 17) - as well as his subsequent proposal, which, in light of her just-prior go-ahead, uses a Modal Declarative format, e-he said well $\underline{I}$ thought maybe we could (.) yihknow have -dinner. (lines 17-18). ${ }^{6}$ Within this particular telling, the proposal for a joint activity constitutes a romantic invitation, which Nancy presents herself as quite excited to have received.

Another environment in which we routinely find Modal Declaratives, but which considerations of space preclude us from reproducing here, is in contexts where recipients have taken a stance, in prior talk or other conduct, that some state of affairs is in some way problematic. This illustrates, we argue, that such stances are taken as displaying a general disposition toward accepting an action that would remedy the oriented-to problem, and speakers use the Modal Declarative format to frame their proposal as a logical means to do just this.

What binds Modal Declarative proposals together is their normative occurrence in environments where recipients have shown themselves to be generally disposed toward acceptance of a proposal or other recruitment-related action. That speakers recurrently use Modal Declaratives to issue proposals in such contexts suggests an orientation to this prior displayed stance, with proposers using a format that indexes an expectation of acceptance, but one that is tentative compared to the stances conveyed with Let's and WDW, which index participants' orientation to relatively greater disposition to accepting the proposal. ${ }^{7}$

\subsection{Modal Interrogatives}

In contrast to the three formats we have seen thus far, used when prior context suggests that compliance with the proposed joint activity is somewhat likely, likely, or all but guaranteed, we find Modal Interrogative proposals in environments where the recipient's prior conduct has not displayed a disposition toward complying with the to-be-proposed joint activity. For this reason, speakers often

6. Note also the I thought formulation which, as Stevanovic (2013) has shown for Finnish data, allows the speaker to not impose a joint decision on the recipient.

7. The issues of lexical choice and tense in Modal Declaratives (e.g., we can vs. we could vs. we should) are too complex to present here, and thus we leave these as matters for future research. 
use this format to propose what might be conceived of as 'new' joint activities that is, joint activities that have so far remained unmentioned, and which, in fact, may not be projected or even anticipated as a next step in the activity, based on prior talk and conduct. With the Modal Interrogative format, then, we argue that speakers index a stance of relative uncertainty with regard to recipient compliance with the proposed action, a stance that is well-fitted to the context of this format's occurrence. Notwithstanding this stance of relative uncertainty, though, we argue that the speaker is still issuing a proposal for a joint activity; but it is a proposal the format of which reflects the lack of buy-in from the recipient thus far, and thus implicitly acknowledges that there may be unforeseen reasons for a lack of compliance. By way of its interrogativity, combined with its first-person pural subject we, the speaker names a joint activity and offers it as a proposed, although unprojected and thus new, next step for the recipient to respond to.

Consider Extract (15). Here, Rich and Ann are in the kitchen preparing supper together, and Rich is looking at his cell phone, which shows the recipe the two are preparing.

(15) [JA-11_pasta]

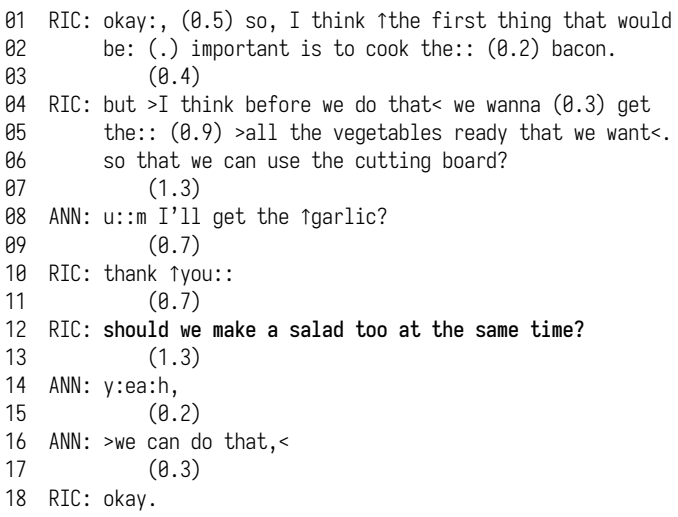

In lines 1-5, Rich lays out an order in which the tasks of the recipe might be carried out, offering an account for this ordering in line 6, so that we can use the cutting board?. Ann demonstrates her approval of his plan by announcing that she'll get the $\uparrow$ garlic? (line 8 ) and moving her body to do so, thereby actively participating in Rich's plan to get the:: (o.9) >all the vegetables ready that we want<. (lines 4-5). After Rich thanks her (line 10), he formulates a 'new' proposal - namely that salad-making might go on at the same time as the vegetablecutting. While this joint activity is certainly relevant to the agreed-upon activity of getting >all the vegetables ready that we want< (line 5), there has been no prior discussion of salad-making (note the indefinite article: $a$ salad), let alone concurrent salad-making, and thus Ann has not shown herself to be disposed toward 
doing this particular joint activity at this time. It is an unprojected next step, based on prior talk and shared understanding of how to make the dish they're preparing. In this context, Rich uses a Modal Interrogative format - should we make a salad too at the same time? (line 12) - to issue his proposal, thereby taking the stance that this joint activity may or may not be agreeable to Ann. In this case it is, and Ann endorses the proposal in lines 13 and 15.

A similar usage is found in Extract (16). Here, Kayla and Sara have just placed a small frying pan on the stove in which they will cook some salmon patties. In line 1 , and then again in lines $16-17$, Sara is reading the package instructions for the patties to Kayla while the pan is preheating.

(16) [JA-12_brownies_o:14]

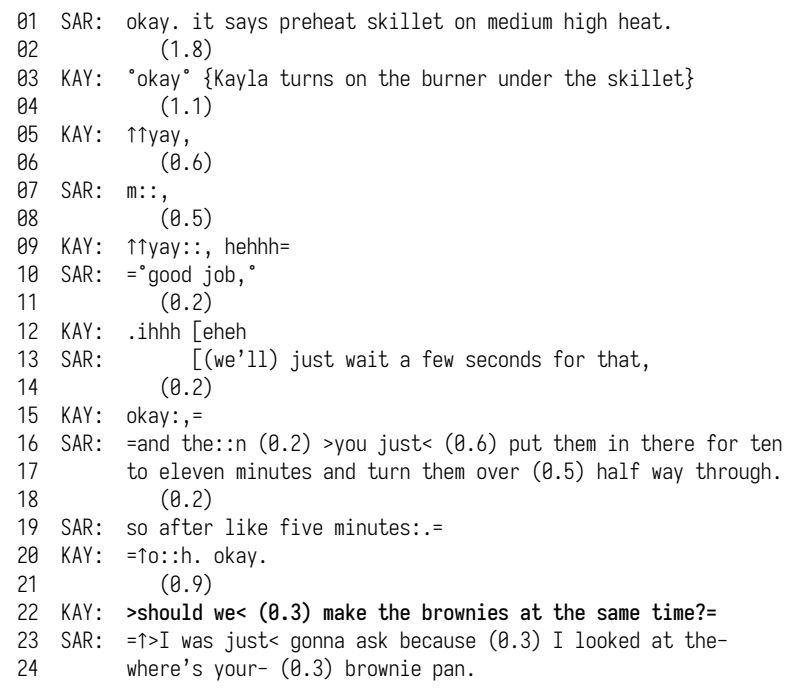

In light of the fact that the patties won't need attention for like five minutes: (line 19), Kayla proposes making brownies while the patties are heating, $>$ should we< (0.3) make the brownies at the same time? (line 22). Although there was indeed a plan to make brownies as part of this cooking activity (note the definite article: the brownies), making them concurrently has not yet been discussed, and is not projectable from their prior talk or prior actions. In this environment, Kayla formats her proposal with a Modal Interrogative, taking the stance that the joint activity of making brownies at the same time as the salmon patties are heating may or may not be acceptable to Sara. Here, Sara claims to have been about to propose the same thing, producing a latched $\uparrow>I$ was just $<$ gonna ask... (line 23). That Sara formulates what she was "'gonna" do with ask - a verb with inherent interrogativity (cf. I was just gonna say; Küttner \& Raymond, frth.) - provides additional support for our argument that an interrogative format is well suited 
to issuing this particular joint-activity proposal at this particular moment in the interaction, since they have not yet discussed whether to undertake these activities simultaneously.

With a Modal Interrogative, then, speakers are indexing relative uncertainty as to whether the recipient is likely to agree to the proposal. As we will argue in the discussion section, interrogative grammar does not preclude a turn-at-talk from issuing a proposal. In fact, we suggest that the proposal-issuing work of a Modal Interrogative is enhanced by being interrogative: it displays an awareness of possible contingencies making its acceptance less certain than with the other proposal formats.

\section{Discussion}

In this study, we have examined the four most frequent verbal-grammatical formats that are used in our data to issue proposals for joint activities in American English interaction. We have suggested that speakers formulate their proposals in terms of what they take to be the recipient's displayed or implied disposition toward accepting the proposal. That is, proposers choose among these grammatical formats according to how strongly the recipient is understood to be disposed toward accepting the proposal, as schematized in (5), repeated here as (17):

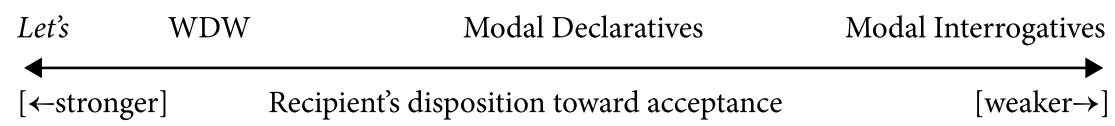

While we have focused primarily on recipients' publicly displayed dispositions, revealed through their prior talk and embodied conduct, it bears underscoring that there are also cases where such dispositions are assumed or otherwise attributed. In case (9), for instance, let's play Asshole (the card came) relies specifically on the absence of a publicly displayed stance toward doing this activity in the context of the reported-speech telling; it is in this way that the speaker leverages the grammatical design of the reported proposal as 'evidence' in support of her complaint.

In what follows, we unpack the schematic characterization in (17) to explore in greater detail the relationship between grammar and social action.

\subsection{The action of proposing a joint activity}

It is noteworthy that three of the four most frequent grammatical formats for issuing a proposal are offered in contexts where recipients have shown themselves to 
be at least somewhat disposed toward endorsing the joint activity. Reconsidering the numbers from Table 1, three formats, Let's $(n=56)$, WDW $(n=11)$, and Modal Declaratives $(n=86)$, together make up 93\% $(n=153)$ of our proposals, compared to Modal Interrogatives at only $7 \%(n=9)$. What does this tell us about the action of proposing a joint activity?

First, these descriptive statistics suggest that speakers perform the action of proposing a joint activity most often in contexts where they already have evidence to suggest that their proposal will be successful. This finding is consistent with what we know about the preference-organizational features of other recruitmentrelated actions, in that speakers deploy them in contexts where their success is more 'likely'. So just as inviters may use some sort of pre-sequence action to check availability prior to the issue of the invitation itself (Schegloff 2007), with a goahead response paving the way for that base action, so too can would-be proposers produce actions to 'feel out' recipients' disposition toward acceptance of a proposal for joint activities. This finding therefore patterns with the more overarching preference for agreement in interaction (Sacks 1987; see also Heritage \& Raymond 2021 and Robinson 2020). Importantly, this may also suggest that American English speakers may turn to other action types when there is no such prior evidence of a disposition in favor of their proposal. That is, proposals for joint activity might in fact be 'avoided' in such contexts and other actions issued instead. Future research in this area might therefore be geared toward how proposals for joint activities intersect with other actions - both other types of proposals, as well as other actions more broadly, and how grammar is implicated in the formulation of those actions.

Second, our analysis clearly reveals that, in proposing a joint activity, speakers orient to fine-grained distinctions in recipient disposition, and they use grammar to do so. While a proposal in any form presents an activity for recipients to subsequently either endorse or reject, we have argued that speakers design their proposals specifically to reflect how disposed they take the recipient to be toward accepting the proposal. These dispositions, we have argued, are typically made publicly available - and thereby accountable - in and through the participants' prior talk and embodied conduct, or are attributed by proposers based on their knowledge of the recipient or the context. In some cases, for instance, a speaker is issuing a proposal in an environment where recipients have already shown themselves to be on board with the whole of this specific proposed course of action (and, in some instances, are already beginning to implement it). Such a strong disposition toward acceptance on the part of the recipient, we argue, provides an account for a particular stance to be taken that frames the success of the proposed joint activity as all but guaranteed. In other cases, though, recipient compliance is not so strongly foreshadowed by prior talk and embodied conduct. For exam- 
ple, perhaps the recipient has oriented to some state of affairs as problematic. On the one hand, this might be taken as displaying a disposition toward accepting a proposal that would resolve the problem. On the other hand, however, the recipient has not shown him- or herself to be disposed toward this particular solution (i.e., this particular joint activity), and so success may not be 'guaranteed. We find that participants orient to these subtle, emergent contingencies in the grammatical design of proposals for joint activity, formulating their actions to enact stances that are fitted to, and accounted for by, the contexts of their deployment. As a cline reflecting recipients' disposition toward acceptance has also been shown to affect the design of offers and imperatives (see Raymond, et al. 2021; Zinken \& Deppermann 2017), our findings further support the claim of speakers' consistent orientation to recipients' buy-in as a truly fundamental dimension of the grammar of recruitment-related actions. Continued exploration of the relevance of this cline across action types seems highly warranted.

\subsection{The grammar of proposing a joint activity}

Our analysis underscores the fact that the grammar used in the design of proposals cannot be understood without reference to the action's environment of occurrence - that is, where the action is being deployed within the immediacy of moment-by-moment conduct. In light of this empirical approach, we are now in a position to explore the fittedness of the particular grammatical forms analyzed here to the contexts of their usage. That is, we can now turn to the question, why are these particular grammatical formats used where they are used, and why do they emerge in this particular way on the cline that we have presented in $(5) /(17)$ ?

We note first that all of the forms we have examined are irrealis. Even the declarative formulations are marked with modals and thus do not make statements about how things are, but rather how things could, should, etc. be. These forms are thus all clearly fitted to the action of proposing future or possible courses of action, which at the moment of the speech event have not yet been realized. Consider now each of these irrealis grammatical formulations vis-à-vis one another.

The Let's format has been characterized as having a 'hortative' function. The grammatical status of a 'hortative' mood cross-linguistically is debated. Some treat it as part of the imperative family, while others consider it a separate grammatical category (see, e.g., Aikhenvald 2010; Alcázar \& Saltarelli 2014; Stevanovic 2017). In considering the relation between its form and the work it does, we find evidence for both these approaches to Let's in our joint-activity data. On the one hand, the Let's format is similar to an imperative in that it is used to propose a joint activity in contexts where there is already strong ongoing sup- 
port for that proposed joint activity. Moreover, like an imperative, it takes a relatively strong deontic stance that the speaker has the right to say what activities the group should undertake - in our cases, because prior context strongly suggests that recipients are on board with what is being proposed. On the other hand, though, the usage of Let's that we have focused on here does not issue a directive to a second person, but rather proposes that first and second person undertake an activity together. ${ }^{8}$ This inclusion of the speaker in the framing of who will actually do the proposed action makes these Let's-formatted actions quite different from the other members of the imperative family, and suggests they may indeed form their own category. The affordances of the unique morphosyntactic form of the Let's format, then, are both similar to, and distinct from, an imperative, and are thus fitted to the deontically strong joint-activity contexts in which English speakers use it to issue their proposals.

The second format on our cline - Why don't we (WDW) - is related to, but different from, similar Why-don't formats such as Why don't I and Why don't you. In their study of Why don't you (WDY) as a vehicle for giving advice, CouperKuhlen and Thompson (forthcoming) argue that this fixed expression is not a 'true' why-question in that it does not make relevant the provision of an account; rather, it offers a suggestion for the recipient to consider. The same finding holds for our cases of Why don't we. In its use to issue a compromise after trouble has arisen with a prior proposal, WDW offers a slightly different version of the proposal rather than pursuing an account for something the participants are not going to do. So why do speakers use a negative $w$-question that looks like it should be an account solicitation (Robinson \& Bolden 2010) or a complaint, for making a compromise proposal after concerns have been expressed about a prior proposal? Couper-Kuhlen and Thompson's study of Why don't you offers this perspective:

In contrast to an imperative form, which treats the feasibility of the action being advocated as beyond doubt, a WDY format in advice-implicative contexts allows that there might be reasons preventing the recipient from acting on the advice. Despite its formulaicity, a WDY format still carries traces of its compositional meaning with the word 'why'. This word raises the issue of accountability in connection with the future action; it suggests that a departure from what would be 'typical' needs an excuse (Robinson 2016:13). In doing so, it allows for the possibility of contingencies that would prevent the recipient from following the advice. If there are such contingencies, the recipient can present these in next turn as a way of resisting or rejecting the advice.

(forthcoming; ms. 27)

8. Cf. Davies (1979) who thus calls it a 'joint imperative' 
We can adopt this understanding in our analysis of WDW. Because a Why don't we proposal also "carries traces of its compositional meaning with the word why", the WDW format can be used to give the recipient an opportunity to offer an account for why they might not accept the proposal, which is well suited to the environment of compromise proposals. This opportunity is in contrast to our Let's cases, which, like imperatives, treat accepting the proposal as highly likely to be accepted, and do not grammatically offer an opportunity to account for not accepting it.

As for the next format on our cline, Modal Declaratives, we note that declaratives make statements, and in our case they make statements regarding joint activities that could or should take place. We have shown that Modal Declaratives often either follow a generic pre-sequence or arise in the context of a problem in continuing with the joint activity. The hypothetical should or could Modal Declarative statement, then, carries relatively less deonticity; the recipients have not shown themselves to be completely on board with the current, particular proposal, and thus the speaker of the Modal Declarative takes a weaker deontic stance toward the likelihood of its acceptance (and routinely mitigates the proposal further with qualifiers like I think and maybe).

As we then consider the Modal Interrogative format, we find that it is deontically the weakest. With its interrogative grammar, it poses a question regarding a possible next course of action and thus makes sequentially relevant acceptance or rejection from the recipient. That is, Modal Interrogatives do not assert how things could or should be, but instead actively seek input from the recipient through the morphosyntactic mobilization of response. They are thus appropriate for, and regularly found in, environments in which the action proposed is an unprojected next step in the larger activity and thus has not been discussed yet, and which the recipient has displayed no disposition to accept. The speaker produces the proposal to check on whether or not the action is one that is appropriate to take next. The predominence of should in these proposals attends to the 'appropriateness' of the action at this moment.

\section{Conclusion: Grammar in the service of deontic symmetry}

In this paper, we have argued that the four grammatical formats explored here can be situated along a cline. This cline indexes the speaker's estimation of how disposed the recipient is toward accepting the emergent proposal. To conclude, we explore the underlying interactional principles shaping proposals and their grammatical manifestations. 
From our discussion so far, the astute reader will have noted that there appears to be a parallel relationship between the assumed degree of disposition to engage in the joint activity embodied by the grammatical format, and the deontic strength of that format. Deontically stronger forms, like Let's, are used to embody a stance that the recipient is highly disposed to accepting the proposal, while deontically weak forms, like the Modal Interrogatives, are used to embody a stance that the recipient has displayed no such disposition to accept the proposal. This relationship can be visualized as a cline parallel to the one we've posited for 'disposition toward acceptance':

\begin{tabular}{|c|c|c|c|}
\hline & WDW & Modal Declaratives & Modal Interrogatives \\
\hline
\end{tabular}

Why would this kind of relationship between deontic strength and disposition-toaccept be at work in proposals for joint activity? We argue that the pattern arises in the service of creating what Stevanovic (2013) has referred to as 'deontic symmetry' between the participants. We base this claim on the fact that if the speaker wanted to claim deontic authority over an action, they could, for example, use Let's to propose an action for which the recipient had shown no previous disposition to accept. Such a move, with its stance that essentially assumes recipient compliance, would place the recipient in a deontically inferior position regarding the proposed joint activity. It is therefore noteworthy that such a usage does not occur in the data we have considered here - mundane, everyday conversations among family members and friends (but recall our discussion of the reportedspeech case (8)). Rather, we find speakers adjusting their grammatical choice to precisely fit the extent to which the recipient has displayed themselves to be disposed toward the proposed activity. Deontically strong forms are used only when recipients have already displayed a strong buy-in to the activity, the strength of the format reflecting degree of collaboration already expectable at that moment in the interaction. ${ }^{9}$ And at the other end of the cline, deontically weak forms (interrogatives) grammatically invite buy-in from a recipient who has not yet shown themselves to be so disposed. We have focused here on extracts illustrating the normative situation, where proposal formats are fitted to their contexts and recipient dispositions are relatively transparent. But of course there are cases where recipient disposition is less transparent and the speaker has to in effect 'place a

9. Here we find a parallel in Wootton's (1997) study, which showed that children making requests of their caregivers were likely to use a (deontically strong) imperative just when "the requested action was consistent with a line of action that she and her parent had agreed on earlier in the interaction" [emphasis ours], that is, just when the child had reason to judge that her request was likely to be granted. 
bet' on the right format; there are also cases where speakers use the 'wrong' format to do special work.

We posit that what participants are doing with these grammatical formats, by means of orienting to the recipient's disposition to accept, is working to ensure that deontic symmetry is constituted and maintained. Deontic symmetry is not a 'given' state of affairs for participants, but rather must be "talked into being" (Heritage 1984b:290) in and through participants' contributions to the interaction; it is a form of collaboration that is itself an interactional achievement. The grammatical formats used to issue proposals for joint activity are one set of concrete practices through which participants actively talk deontic symmetry into being. The result of this interactional work is the constitution of a deontic landscape in which neither participant claims authoritative rights or responsibilities to control the movement of the other as they pursue collaborative activities; that is, the participants in our data are working to construct themselves, and one another, as having joint decision-making roles in the process. And, in the grammatical design of proposals, we argue that it is precisely the orientation to recipients' displayed disposition toward acceptance that provides for the achievement of a symmetrical deontic landscape. In this way, the set of practices reviewed here support Tomasello's (2014) claim that humans are 'especially cooperative' by showing how participants demonstrably work to align their multiple wishes, desires, needs, and concerns as they negotiate and carry out joint activities.

\section{Acknowledgements}

We are grateful to Kobin Kendrick for sharing his annotated data on proposals with us. We also benefitted from the input received from Barend Beekhuisen, Elizabeth Couper-Kuhlen, Melisa Stevanovic, the editors of Interactional Linguistics, and two anonymous reviewers. We alone are responsible for any infelicities that may remain.

\section{References}

Aikhenvald, A.Y. (2010). Imperatives and commands. Oxford: Oxford University Press. Alcázar, A. \& Saltarelli, M. (2014). The syntax of imperatives. Cambridge: Cambridge University Press.

Asmuß, B. \& Oshima, S. (2012). Negotiation of entitlement in proposal sequences. Discourse Studies 14(1):67-86. https://doi.org/10.1177/1461445611427215

Barnes, R. (2007). Formulations and the facilitation of common agreement in meetings talk. Text \& Talk 27(3):273-296. https://doi.org/10.1515/TEXT.2007.011

Bolden, G. B. \& Robinson, J.D. (2011). Soliciting accounts with why-interrogatives in conversation. Journal of Communication 61(1):94-119. https://doi.org/10.1111/j.146o-2466.2010.01528.x 
Bybee, J.L. (2010). Language, usage and cognition. Cambridge: Cambridge University Press. https://doi.org/10.1017/CBO9780511750526

Clayman, S. E. \& Heritage, J. (2014). Benefactors and beneficiaries: benefactive status and stance in the management of offers and requests. In E. Couper-Kuhlen \& P. Drew (Eds.), Requesting in social interaction, (55-86). Amsterdam: Benjamins. https://doi.org/10.1075/slsi.26.03cla

Clift, R. \& Raymond, C.W. (2018). Actions in practice: On details in collections. Discourse Studies, 20(1):90-119. https://doi.org/10.1177/1461445617734344

Couper-Kuhlen, E. (2014). What does grammar tell us about action? Pragmatics 24(3),623-647. https://doi.org/10.1075/prag.24.3.08cou

Couper-Kuhlen, E., \& Thompson, S.A. (Frthc.). Action ascription in everyday advice-giving sequences. In A. Depperman \& M. Haugh (Eds.), Action ascription: interaction in context. Cambridge: Cambridge University Press.

Curl, T.S. (2006). Offers of assistance: constraints on syntactic design. Journal of Pragmatics, 38:1257-128o. https://doi.org/10.1016/j.pragma.2005.09.004

Curl, T.S. \& Drew, P. (2008). Contingency and action: a comparison of two forms of requesting. Research on Language and Social Interaction 41(2):1-25. https://doi.org/10.1080/08351810802028613

Davies, E. (1979). On the semantics of syntax: mood and condition in English. London: CroomHelm.

Du Bois, I. (2012). Grammatical, pragmatic and sociolinguistic aspects of the first person plural pronoun. In N. Baumgarten, I. Du Bois, \& J. House (Eds.). Subjectivity in language and in discourse (319-338). Leiden: Brill.

Floyd, S., Rossi, G., \& Enfield, N. J. (Eds). (2020). Getting others to do things, A pragmatic typology of recruitments. Berlin: Language Sciences Press.

Fox, B.A. \& Heinemann, T. (2016). Rethinking format, an examination of requests. Language in Society 45(4):499-531. https://doi.org/10.1017/So047404516000385

Goodwin, M.H. (1990). He-said-she-said: talk as social organization among black children. Bloomington: Indiana University Press.

Haiman, J. (1998). Talk is cheap, sarcasm, alienation, and the evolution of language. Oxford: Oxford University Press.

Heritage, J. (1984a). A change-of-state token and aspects of its sequential placement. In J.M. Atkinson \& J. Heritage (Eds.), Structures of social action (299-345). Cambridge: Cambridge University Press.

Heritage, J. (1984b). Garfinkel and Ethnomethodology. Cambridge: Polity Press.

Heritage, J. \& Raymond, C.W. (2021). Preference and polarity: Epistemic stance in question design. Research on Language and Social Interaction 54.1: 39-59. https://doi.org/10.1080/08351813.2020.1864155

Hoey, E. (2020). Self-authorizing action: On let me X in English social interaction. Language in Society. https://doi.org/10.1017/So047404520000779

Hoey, E. \& C.W. Raymond. (Frthc.). Managing data in conversation analysis. In A. Berez-Kroeker, B. McDonnell, \& E. Koller (Eds.), The open handbook of linguistic data management. Cambridge: MIT Press.

Holt, E. (1996). Reporting on talk: the use of direct reported speech in conversation. Research on Language and Social Interaction 29(3):219-245.

https://doi.org/10.1207/s15327973rlsi2903_2 
Houtkoop, H. (1987). Establishing agreement. Dordrecht: Foris. https://doi.org/10.1515/9783110849172

Kendrick, K.H. \& Drew, P. (2016). Recruitment, Offers, requests, and the organization of assistance in interaction. Research on Language and Social Interaction 49(1):1-19. https://doi.org/10.1080/08351813.2016.1126436

Koshik, Irene. 2002. Designedly incomplete utterances: a pedagogical practice for eliciting knowledge displays in error correction sequences. Research on Language and Social Interaction 5.3: 277-309. https://doi.org/10.1207/S15327973RLSI3503_2

Küttner, U-A. \& C.W. Raymond. (Frthc.). 'I was gonna say...': preliminary observations on the doubly reflexive character of a meta-communicative practice. LiLi, Studien $z u$ Literaturwissenschaft und Linguistik.

Lindström, A. (2017). Accepting remote proposals. In G. Raymond, G. H. Lerner, \& J. Heritage (Eds.), Enabling human conduct: studies of talk-in-interaction in honor of Emanuel A. Schegloff, (125-142). Amsterdam: Benjamins. https://doi.org/10.1075/pbns.273.07lin

Raymond, C.W., Robinson, J.D., Fox, B.A., Thompson, S.A., \& Montiegel, K. (2021). Modulating action through minimization: Syntax in the service of offering and requesting. Language in Society 50.1: 53-91. https://doi.org/10.1017/S004740452000069X

Robinson, J.D. (2016). Accountability in social interaction. In J. D. Robinson (Ed.), Accountability in social interaction (3-46). Oxford: Oxford University Press. https://doi.org/10.1093/acprof:0so/9780190210557.003.0001

Robinson, J.D. (2020). One type of polar, information-seeking question and its stance of probability: Implications for the preference for agreement. Research on Language and Social Interaction 53(4), 425-442. https://doi.org/10.1080/08351813.2020.1826759

Robinson, J.D. \& Bolden, G. B. (2010). Preference organization of sequence-initiating actions: the case of explicit account solicitations. Discourse Studies 12(4):501-533. https://doi.org/10.1177/1461445610371051

Robinson, J.D. \& Kevoe-Feldman, H. (2016). The accountability of proposing (vs. soliciting proposals of) arrangements. In J.D. Robinson (Ed.), Accountability in social interaction (264-293). Oxford: Oxford University Press. https://doi.org/10.1093/acprof:oso/9780190210557.003.0009

Sacks, H. (1987[1973]). On the Preferences for Agreement and Contiguity in Sequences in Conversation. In G. Button \& J. R.E. Lee (Eds.), Talk and social organisation (54-69). Clevedon: Multilingual Matters.

Sacks, H. \& E.A. Schegloff. (1979). Two preferences in the organization of reference to persons and their interaction. In G. Psathas (Ed.), Everyday language, studies in Ethnomethodology (15-21). New York: Irvington Publishers.

Schegloff, E.A. (2007). Sequence organization in interaction: a primer in conversation analysis Volume 1. Cambridge: Cambridge University Press. https://doi.org/10.1017/CBO9780511791208

Stevanovic, M. (2012). Establishing Joint Decisions in a Dyad. Discourse Studies 14(6):779-803. https://doi.org/10.1177/1461445612456654

Stevanovic, M. (2013). Constructing a proposal as a thought: a way to manage problems in the initiation of joint decision-making in Finnish workplace interaction. Pragmatics 23(3):519-544. https://doi.org/10.1075/prag.23.3.07ste

Stevanovic, M. \& Peräkylä, A. (2012). Deontic authority in interaction: the right to announce, propose, and decide. Research on Language and Social Interaction, 45(3):297-321. https://doi.org/10.1080/08351813.2012.699260 
Stevanovic, M., Valkeäpää, T., Waiste, E., \& Lindholm, C. (2020). Joint decision making in a mental health rehabilitation community: the impact of support workers' proposal design on client responsiveness. Counseling Psychology Quarterly. https://doi.org/10.1080/09515070.2020.1762166

Stivers, T. (2004). "No no no" and other types of multiple sayings in social interaction. Human Communication Research, 30(2):260-293. https://doi.org/10.1111/j.1468-2958.2004.tboo733.x

Stivers, T. \& Sidnell, J. (2016). Proposals for activity collaboration. Research on Language and Social Interaction 49(2):148-166. https://doi.org/10.1080/08351813.2016.1164409

Thompson, S.A., Fox, B.A., \& Couper-Kuhlen, E. (2015). Grammar in everyday talk: Building responsive actions. Cambridge: Cambridge University Press. https://doi.org/10.1017/CBO9781139381154

Tomasello, M. (2014). The ultra-social animal. European Journal of Social Psychology 44(3):187-194. https://doi.org/10.1002/ejsp.2015

Wootton, A. J. (1997). Interaction and the development of mind. Cambridge: Cambridge University Press. https://doi.org/10.1017/CBO9780511519895

Zinken, J. \& Deppermann, A. (2017). A cline of visible commitment in the situated design of imperative turns. In M-L. Sorjonen, L. Raevaara \& E. Couper-Kuhlen (Eds.), Imperative turns at talk: the design of directives in action (27-64). Amsterdam: Benjamins. https://doi.org/10.1075/slsi.30.02zin

Zinken, J. \& Ogiermann, E. (2011). How to propose an action as objectively necessary: The case of Polish trzeba $x$ ("One needs to $\mathrm{x}$ "). Research on Language and Social Interaction 44(3):263-287. https://doi.org/10.1080/08351813.2011.591900

\section{Address for correspondence}

Sandra A. Thompson

Department of Linguistics

UC Santa Barbara

1078 Via Los Padres

Santa Barbara, CA 93111-1345

USA

sathomps@linguistics.ucsb.edu

https://orcid.org/oooo-0oo2-7794-2042

\section{Co-author information}

Barbara A. Fox

Department of Linguistics

University of Colorado
Chase Wesley Raymond

Department of Linguistics

University of Colorado, Boulder 


\section{Publication history}

Date received: 8 September 2020

Date accepted: 2 March 2021

Published online: 6 May 2021 